\title{
Resilience in Women who Experience Domestic Violence
}

\author{
Konstantinos Tsirigotis ${ }^{1}$ • Joanna Luczak ${ }^{1}$
}

Published online: 12 August 2017

(C) The Author(s) 2017. This article is an open access publication

\begin{abstract}
Violence in the family constitutes a serious social and psychological problem with harmful consequences leading, among others, to changes in the psychological functioning of the victim and, secondarily, also the perpetrator. The aim of this study was to examine resilience in women experiencing domestic violence. The "Ego Resiliency Scale" (ERS) was used to study the group of women suffering domestic violence. The study group included 52 women aged 30 65 years (mean age: 40.15) using assistance of the Crisis Intervention Centre due to experienced domestic violence. They most often reported suffering psychological and physical violence, with the husband or intimate partner being the most common perpetrator. Study women experiencing domestic violence obtained significantly lower scores on the ERS. The lowest scores on the ERS were achieved by women suffering paternal violence, while the highest - by women experiencing violence on the part of the intimate partner. Resilience of study women suffering domestic violence was lower than resilience of the general population, i.e. individuals not experiencing domestic violence. Suffered violence inflicted by the father exerted the greatest adverse impact on resilience. It seems advisable to consider resilience in the process of providing women experiencing domestic violence with psychosocial help.
\end{abstract}

Keywords Resilience $\cdot$ Domestic violence $\cdot$ Women

MOTTO: ... growth and pain are not mutually exclusive but rather inextricably linked in recovery from trauma and loss (Saakvitne K.W., Tennen H., Affleck G.).

\section{Introduction}

The phenomenon of violence in the family (domestic violence, DV and intimate partner violence, IPV) is a common one more often affecting women: violence against women is a

Konstantinos Tsirigotis

psyche1@onet.eu; konstantinos.tsirigotis@ujk.edu.pl; k.tsirigotis@unipt.pl

1 Department of Psychology, The Jan Kochanowski University in Kielce, Piotrków Trybunalski Branch, Słowackiego 114/118 str, 97-300 Piotrków Trybunalski, Poland 
global public health problem that besets approximately one third of women globally [cf. 1-3]. Violence in the family constitutes a serious social and psychological problem with harmful consequences for individuals who both experience violence and resort to it, leading, among others, to changes in the psychological functioning of the victim and, secondarily, also the perpetrator. Violence in the family may arise from emotionality disorders, personality disorders or psychotic disorders of the perpetrator, but it, certainly, also results from disturbances in relations between partners (regardless of the source of those disturbances) [4].

Although the notions of domestic violence and intimate partner violence are very similar to each other, as both assume experiencing violence inflicted by very close people, this study is going to deal with domestic violence as a broader concept, encompassing not only violence perpetrated by the intimate partner, but also by other family members. Violence in the family may concern all its members; it can also be of the mutual nature. In the case of physical violence, however, perpetrators tend to be men [5]. The essence of domestic violence is the use of an advantage of power or authority in order to harm the other family members. Browne and Herbert distinguish among physical, psychological and sexual violence, drawing attention to its active or passive forms and intensity. Domestic violence victims experience anxiety, suffering, helplessness, dispiritedness, and despair. Their bodies and psyches suffer acute injuries and are subject to processes of damaging and protracted stress and threat $[4,6]$.

Various authors understand domestic violence in a similar way. Domestic violence is defined as male aggression toward a female partner [7]. Domestic violence against women can be defined as any act or omission which, based on gender, causes death, physical, sexual or psychological injury, and moral damage to women; it can be inflicted by individuals with or without family ties who are either related by natural bonds, by affinity or by express will, including sporadic relationships [8]. Due to the significance of the problem, it also gained the attention of international organisations. Domestic violence is understood as all acts of physical, sexual, psychological or economic violence that occur within the family or domestic unit or between former or current spouses or partners, whether or not the perpetrator shares or has shared the same residence with the victim [9]. Authors of that point of view draw attention to the fact that it is not the current place of residence of the perpetrator or the ongoing nature of the relationship with the victim that are the most important. The United Nations Declaration on the Elimination of Violence Against Women [10] defines violence against women taking place in the family in the following way: "Physical, sexual and psychological violence occurring in the family, including battering, sexual abuse of female children in the household, dowryrelated violence, marital rape, female genital mutilation and other traditional practices harmful to women, non-spousal violence and violence related to exploitation". A similar phenomenon/ term is the battering relationship defined as the repeated use of physical, sexual or verbal force by someone against his intimate partner [11].

In Poland, the definition contained in the national programme of violence prevention in the family is most commonly accepted. It describes violence as any action, intended and using an advantage of power, directed against a family member, which infringes his or her personal rights and interests, causing suffering and harm [12]. Another definition mentioned in Polish literature presents domestic violence as actions or glaring neglects on the part of a family member against the others, using an existing advantage of power or authority, or such an advantage created by circumstances, and causing harm or suffering to the victims, infringing their personal rights and, in particular, damaging their lives or (physical or mental) health [6].

Violence against women is not harmless; it produces numerous undesirable and adverse outcomes. Abused women are at increased risk of depression, anxiety, posttraumatic stress 
disorder and suicide, as well as physical problems [13]. Physical violence is associated with injuries (e.g. bruises, knife wounds, broken bones, headaches, back or pelvic pain, and death). Psychological abuse typically accompanies physical one, and the consequences of such abuse include depression, anxiety, posttraumatic stress disorder, and attachment disorders. Domestic violence has also been linked to increased adverse psychological and behavioural outcomes, such as smoking, drinking, taking drugs (i.e. substance abuse) or having unprotected sex, and other negative mental and physical health consequences [14].

For some time now, resilience or resiliency have more and more commonly been mentioned as yet another psychological resource. Research on resilience was initially conducted on children's populations as first observations in that scope concerned children raised in families where at least one parent suffered from schizophrenia [cf. 15]; hence, world literature offers a considerable number of publications on resilience as a trait and/or process mainly in children. That was possibly due to the fact that children are characterised by higher flexibility and plasticity of the (central) nervous system and psychological functioning. It was only later that resilience began to be studied in adults. Many authors use the term "resiliency" as synonymous with the term "resilience" [cf. 16-18].

What the notions of "mental immunity", "mental hygiene", "mental resilience", "emotional resilience" or "mental health resilience" have in common is the aim of broadening mental health research concepts, beyond risk factors for pathology, to include wellness enhancement and health promoting factors; a range of studies have suggested that "resilience" can be seen as synonymous with reduced "vulnerability", with ability to adapt to adversity or to "cope" [19].

Resilience has been defined as the maintenance of healthy/successful functioning or adaptation within the context of a significant adversity or threat and is better characterised as a dynamic process, since individuals can be resilient to specific environmental hazards or resilient at one time but not another [7, 15]. It is a relative capacity for healthy adaptation to life adversities [20]. Resilience is considered a positive personality characteristic enhancing individual adaptation [21]. Resilience is conceived as a dynamic developmental process encompassing the attainment of positive adaptation within the context of significant adversity [22-25]. There are two critical conditions that are implicit within this conceptualisation of resilience: a) exposure to a significant threat, severe adversity or trauma; b) the achievement of positive adaptation despite major assaults on the developmental process [22, 24, 25]. Resilience is not something an individual "has" - it is a multiply determined developmental process, which is not fixed or immutable [25]. Resilience is also understood as a dynamic process in which psychological, social, environmental and biological factors interact to enable an individual at any stage of life to develop, maintain, or regain her/his mental health despite exposure to adversity [26].

The concept of resilience is used to describe the ability of the individual or group to face adversity positively, even when the environment is unfavourable. Resilience is characterised by human capacity to respond to everyday life demands in a positive way, despite adversities faced throughout the development of her/his life cycle, resulting in the combination of individual attributes and her/his family, social and cultural environments. Resilience is composed of two dimensions: resistance to destruction that relates to the ability to protect one's integrity under strong pressure; and the ability to build or create a life worth living despite adverse circumstances [8].

Some researchers have investigated resilience as an individual trait or an epiphenomenon of adaptive temperament, while others as a process or force that drives a person to grow through adversity and disruption [19]. 
Resilience, previously described as the ability to achieve positive adjustment in spite of adversity, has more recently been defined as a process dependent on a range of ecological factors like family, school, peers, community responsibility, and social justice. Taking into account the multidimensional nature of resilience, some authors categorise resilience on different levels, which they refer to as "resilient", "near-resilient", and "non-resilient" [27].

Resilience may also be understood as the possibility of recovery from and overcoming of adversity, with the objective of strengthening and recovering of the individual, and making her/him emotionally stronger; the process of internal mobilisation, which triggers a movement of breaking away and of openness regarding the other with the aim of helping oneself and being helped, of overcoming the experience and finding new meaning for existence, is termed resilience [28].

To sum up, it can be stated that resilience is a set of personality characteristics, as well as skills and competences, which contribute to coping with stress, trauma, problems and adversities in life. It may be understood not only as a personality trait, but also as complex processes conditioning the adaptation and development of individuals and families facing various threats and adversities [29].

As arises from the above, the notion is consistent with the salutogenic approach in psychology. Resilience can be comprehended as one of the psychological resources enabling the human to cope with an (even extremely) difficult present situation and/or stress, as well as upon its occurrence.

As an interesting side note, it can be added that, although the coining of the term "resilience" is usually ascribed to Garmezy [15] and Werner [30], it was French neuropsychiatrist Boris Cyrulnik who dedicated his life to studies on the development of that concept [28].

Recently, in the framework of exploring psychological resources of women experiencing domestic violence, their emotional intelligence has been studied [4].

As a result of one of the scarce studies on the resilience of women suffering domestic violence, resilience was found to be high in women who had ended a battering relationship [11]. Another study indicated that women were surprised by an act of extreme violence, in which the aggressor tried to kill them, assault them and/or kill their children. The confrontation, which is the first step in the process of resilience, began once they faced the possibility of death: the resilience process started when the aggressor physically attempted to kill them, hurt and/or kill their children [8].

As it stems from the above, world literature offers a very small number of studies into resilience of women experiencing domestic violence.

The aim of this study has been to examine resilience in women suffering domestic violence.

\section{Methods}

\section{Participants}

The study group included 52 women aged 30-65 years (mean age: 40.15) using assistance of the Crisis Intervention Centre (CIC) due to experienced domestic violence. Women reported to the CIC on their own initiative or were referred there by an interdisciplinary team for the prevention of domestic violence and all had a "Blue Card". ${ }^{1}$ The research was conducted by specialists (psychologists) at the start of the intervention, upon informing women about the aim of the study and obtaining their consent to participating in the research.

\footnotetext{
1 "Blue Card" is an important part of the Polish system of intervention strategies against domestic violence existing in Poland since 1998 and is filled at an intervention site in the presence of the perpetrator.
} 


\section{Materials}

In order to assess resilience, this study applied the Polish version of the "Ego Resiliency Scale (ER89)" (ERS) by Block and Kremen [17] as adapted by Kaczmarek [31]. The scale is composed of 14 items, on which the subject may take a position by choosing one of the four possible answers (Likert type scale). Both the original and Polish versions are characterised by high reliability and validity $[17,31]$.

\section{Statistical Analysis}

The statistical analysis of received scores applied descriptive methods and statistical inference methods. In order to determine mean values for quantitative traits, arithmetic means (M) were calculated, while the standard deviation (SD) was assumed to be the dispersion measure. The statistical processing of received scores employed difference testing, multiple regression analysis, analysis of variance by ranks by Kruskal-Wallis (Kruskal-Wallis ANOVA by ranks), and multiple comparisons. For all the analyses, the maximum acceptable type I error was assumed at $\alpha=0.05$. Asymptotic two-sided test probability $\mathrm{p}$ was calculated and $p \leq 0.05$ was considered statistically significant. The statistical analyses were performed by means of the Statistica PL 13.0 statistical package [32].

\section{Results}

Table 1 shows socio-demographic data and Table 2 - domestic violence data of the study group. The data indicate that most women were married (50\%) and had higher education $(40.38 \%)$. The study women reported that they had most often experienced psychological $(96.15 \%)$ and physical $(80.77 \%)$ violence, with the husband $(73.08 \%)$ or intimate partner $(17.31 \%)$ being the most common perpetrator. They had experienced violence for 2 to 25 years (mean time: 7.82). The study women suffering domestic violence obtained ERS scores (M: 34.615; SD: 6.250) significantly lower $(p<0.0000)$ than the general population not experiencing domestic violence (M: 39.564; SD: 5.711).

In order to identify variables being significant predictors of resilience, stepwise multiple regression was used. Table 3 (and Fig. 1) present results of the stepwise multiple regression analysis, in which the dependent variable was resilience (ERS) and independent variables were socio-demographic and violence variables. All the variables were included in the initial

Table 1 Socio-demographic characteristics of the study group

\begin{tabular}{llll}
\hline Variable & & $\mathrm{n}$ & $\%$ \\
\hline \multirow{2}{*}{ Age } & M \pm SD & $39.46 \pm 8.91$ & \\
& Range & $21-65$ & 15.38 \\
Marital status & Single & 8 & 50.00 \\
& Married & 26 & 28.85 \\
& Divorced & 15 & 5.77 \\
& Non-formalised relationship & 3 & 13.46 \\
Education & Primary & 7 & 23.08 \\
& Vocational & 12 & 23.08 \\
& Secondary & 12 & 40.38 \\
\hline
\end{tabular}


Table 2 Violence data of the study group

\begin{tabular}{llll}
\hline Variable & & $\mathrm{n}$ & $\%$ \\
\hline Time & M SD & $7.82 \pm 5.19$ & \\
& Range & $2-25$ & 80.77 \\
Types of Violence/Abuse ${ }^{\mathrm{a}}$ & Physical & 42 & 96.15 \\
& Psychological & 50 & 34.62 \\
& Sexual & 18 & 21.15 \\
Perpetrator & Economical & 11 & 73.08 \\
& Husband & 38 & 17.31 \\
& Intimate Partner & 9 & 5.77 \\
& Father & 3 & 3.84 \\
\hline
\end{tabular}

a The sum of percentages may exceed $100 \%$ because the participants could report more than one type of violence/ abuse

regression equation. As shown in the table, all the variables remained in the regression equation, but not all of them turned out to be significant for resilience. Significant predictors were found to be age ( $\beta$ : $0.364 ; \mathrm{p}: 0.002)$ and perpetrator $(\beta:-0.247 ; 0.01)$. Therefore, the Kruskal-Wallis ANOVA by ranks was used (Table 4) to identify the perpetrator whose violence exerted the greatest impact on resilience intensity, while multiple comparisons (Table 5, Fig. 2) were performed to investigate possible differences in resilience intensity dependent on who committed violence against the women. As a result of the analyses, it was found that the lowest scores on the ERS were obtained by women suffering violence on the part of the father, while the highest - by women experiencing violence inflicted by the intimate partner. ERS scores of women experiencing violence on the part of the father, husband and intimate partner differed statistically significantly from one another.

\section{Discussion}

In the discussion of the results, it will be difficult to refer to results of other research in that field as the authors of this study have not found studies dedicated to that issue in available literature.

Table 3 Stepwise multiple regression (Perpetrator-Resilience)

Dependent (Criterion) Variable: Resilience (ERS)

Coefficient of Multiple Regression $R=0.399$

Coefficient of Determination (R Square) $R^{2}=0.159$

Corrected Determination coefficient (Adjusted R Square) $\mathrm{R}^{2}=0.107$

Significance of the regression eq. $\mathrm{F}(6,45)=3.057 p<0.008$

Std. error of the estimate: 5.877

\begin{tabular}{lllllll}
\hline Independent (predictor) variables & Beta $(\beta)$ & $\begin{array}{l}\text { Std. Err. of } \\
\operatorname{Beta}(\beta)\end{array}$ & Std. B $(\beta)$ & $\begin{array}{l}\text { Std. Err. } \\
\text { of B }(\beta)\end{array}$ & t (46) & p-level \\
\hline Age & 0.364 & 0.119 & 0.256 & 0.084 & 3.045 & 0.002 \\
Education & 0.169 & 0.102 & 0.970 & 0.584 & 1.662 & ns. \\
Marital Status & -0.094 & 0.103 & -0.744 & 0.816 & -0.912 & ns. \\
Types of Violence/Abuse & 0.013 & 0.107 & 0.000 & 0.002 & 0.125 & ns. \\
Perpetrator & -0.247 & 0.097 & -1.995 & 0.787 & -2.534 & 0.01 \\
Time & -0.019 & 0.115 & -0.022 & 0.132 & -0.167 & ns. \\
\hline
\end{tabular}



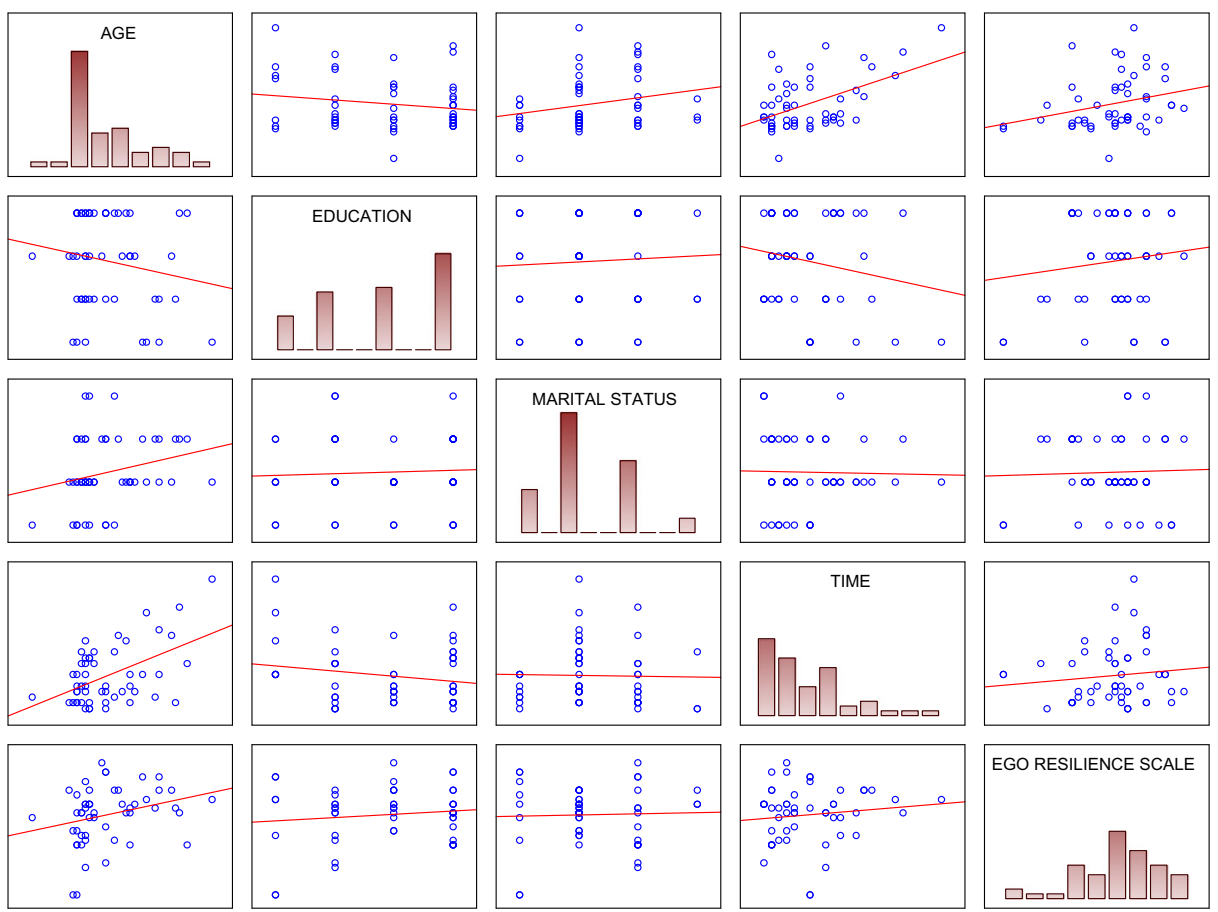

Fig. 1 Scatterplot matrix of the studied variables

The majority of women had higher education; maybe it was their higher education that made them seek help in the CIC. For instance, a complete opposite of such an attitude is the phenomenon consisting in the fact that lower caste women in India are not only more likely to experience discrimination and violence, but they are also more likely to accept unequal treatment and violence as fact of life, keep it to themselves and do not seek help [33, 34]. Besides, seeking help may also be an attempt at saving one's marriage.

Similar results, i.e. psychological violence as the most commonly experienced type of violence, were also received in other research [11]. Although literature mentions psychological, physical, sexual and other forms of violence, they all actually come down to psychological one: firstly, as soon as any other type of violence takes place, it automatically also becomes psychological one; secondly, consequences of every violence type are psychological too.

The lower ERS scores may indicate that experienced violence weakened or even damaged the women's resilience, which is of crucial importance for the process of recovery from trauma [11,

Table 4 Kruskal-Wallis ANOVA by Ranks of scores in the ERS

Independent (grouping) Variable: Perpetrator

Kruskal-Wallis Test: $\mathrm{H}(3, n=52)=11.691 ; p=0.008$

\begin{tabular}{lllll}
\hline & Mean & St. Dev. & Ranks Sum & Mean Rank \\
\hline Husband & 34.737 & 5.197 & 979.000 & 25.763 \\
Intimate Partner & 38.667 & 4.899 & 340.500 & 37.833 \\
Father & 21.000 & 6.928 & 13.500 & 4.500 \\
Mother & 35.000 & 0.010 & 45.000 & 22.500 \\
\hline
\end{tabular}


Table 5 Multiple comparisons of scores in the ERS considering the perpetrator

Independent (grouping) Variable: Perpetrator

Kruskal-Wallis Test: $\mathrm{H}(3, n=52)=11.691 ; p=0.008$

\begin{tabular}{lllll}
\hline & $\begin{array}{l}\text { 1. Husband } \\
(34.737)\end{array}$ & $\begin{array}{l}\text { 2. Intimate Partner } \\
(38.667)\end{array}$ & $\begin{array}{l}\text { 3. Father } \\
(21.000)\end{array}$ & $\begin{array}{l}\text { 4. Mother } \\
(35.000)\end{array}$ \\
\hline $\begin{array}{l}\text { 1. Husband (34.737) } \\
\text { 2. Intimate Partner (38.667) }\end{array}$ & $\begin{array}{l}0.01 \\
\text { 3. Father (21.000) }\end{array}$ & 0.01 & 0.005 & ns. \\
4. Mother (35.000) & ns. & $\begin{array}{l}0.00001 \\
\text { ns. }\end{array}$ & ns. & ns. \\
\hline
\end{tabular}

$28,35]$. That seems logical and consistent, but literature data are not unambiguous. On the one hand, some authors mention adverse consequences of domestic violence in the form of psychological [cf. 36-40] and physical functioning disturbances [cf. 39, 40]; on the other hand, there are studies indicating that women who have ended a battering relationship demonstrate high levels of overall resilience [cf. 11, 41]; and even show both psychological distress and resilience too [cf. $11,21]$. Those studies, however, concern women who were already physically separated from the violence perpetrator (divorced or sheltered), whereas a majority of women experiencing domestic violence in the present study still lived with the perpetrator when the research was carried out.

As we observed, the regression for resilience indicated the age and the person of the perpetrator (with the minus sign) as significant variables. The issue of age seems rather clear: as the woman gains life experience, including by living with the perpetrator, her resilience increases. In turn, among all the studied variables, the weakening or even damaging (the minus sign) of resilience in women experiencing domestic violence is mainly determined by the person of the perpetrator. That is an interesting result worth closer examination.

The above-mentioned ANOVA by ranks and multiple comparisons indicated that violence used by the father most considerably weakened or damaged resilience in the women. The most

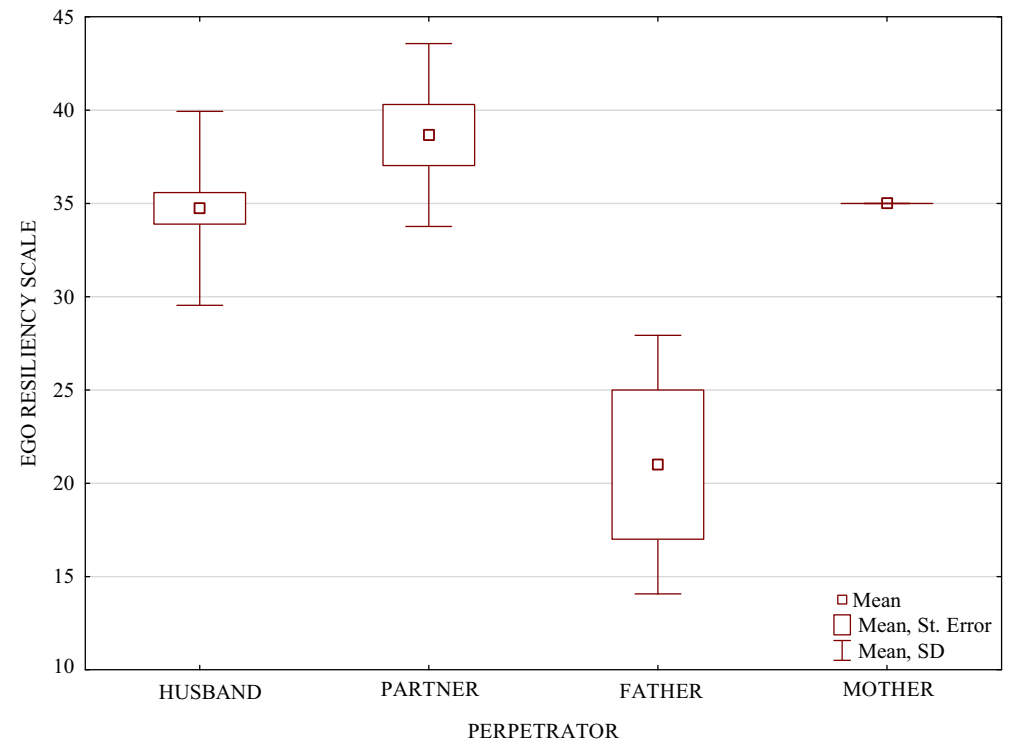

Fig. 2 Resilience of study women regarding the perpetrator 
deleterious impact on their resilience was exerted by violence on the part of the father. That is interesting as the father was not the person most commonly reported as one committing violence against the women (the most common perpetrators were the husband and the intimate partner). Not even referring to Freud's concept [42] of God being a grand sublimation of father, it is known that the father is a very important person for every human, and thus also violence inflicted by him is more strongly felt and leads to more profound consequences, which may be exemplified and reflected by low resilience. In other words, domestic violence on the part of the father may severely weaken/damage resilience since the father is one of the very close people, very significant others and attachment to him and emotional bonds with him are stronger, and expectations from him are higher, hence the greater disappointment, disenchantment, frustration and psychological suffering caused by violence committed by him. It should be noted that violence used by the mother did not exert such a powerful impact on the study women's psychological resources.

In turn, the highest resilience occurred in women experiencing violence on the part of the intimate partner (not the husband); it is worth pondering over because both the husband and the intimate partner are individuals with whom the woman remains in an intimate relationship, and thus very close ones. Violence employed by the intimate partner may weaken/damage resilience to a lesser extent than violence on the part of the father and the husband for at least two reasons. Quite possibly, awareness of splitting with the intimate partner being easier (awareness of reversibility of the state of affairs, hence a way out of the difficult situation) than with the husband makes resilience in the women less weakened/damaged by violence. On the other hand, that involves social, cultural and religious issues. Poles (the study concerned Polish women) are mostly Catholics, especially as one of the latest popes was a Pole. An internal (subjective) factor is the interiorisation of certain norms, principles and values such as, for example, the sacrament of marriage. An external (objective) factor is considerable difficulties in obtaining Church-granted divorce or annulment of marriage by the Church. The factors may bring in the women a sense of being condemned to the relationship, of no way out, irrespective of their will, which may breed a feeling of helplessness being very unfavourable for psychological resources [43]. On the other hand, in the case of the intimate partner, with no or weak impact of the above-mentioned internal and external factors, there is a prospect for the possible ending of a battering relationship and hope of freeing oneself from violence, hence possible higher resilience. The processes may not occur in a relationship with the husband, and much less with the father, and thus violence inflicted by them (particularly by the father) so greatly weakens or damages resilience. It seems that definite answers to the above questions may be provided by results of further studies.

It stems from the above that, along with the earlier known adverse consequences of domestic violence experienced by women in the form of disturbed psychological functioning and physical health, resilience is damaged by that too, which ought to be taken into account when devising and implementing help schemes for those women. Therefore, it seems advisable to also consider that aspect of the psychological functioning of women experiencing domestic violence in actions aimed at providing them with psychosocial help.

\section{Conclusions}

Recapitulating the above findings, one can state that, in the study group of women, psychological violence and physical violence were the most commonly experienced forms of violence, while the person most often inflicting violence against them was the husband. Resilience of study women suffering domestic violence was lower than resilience of the 
general population, not experiencing domestic violence. Experienced violence committed by the father exerted the greatest adverse impact on resilience. The above results may prove useful in therapeutic and prophylactic work with women suffering domestic violence.

Limitations The sample size may be a possible limitation.

Funding There was no funding.

\section{Compliance with Ethical Standards}

Ethical Approval All procedures performed in studies involving human participants were in accordance with the ethical standards of the institutional and/or national research committee and with the 1964 Helsinki declaration and its later amendments or comparable ethical standards.

Informed Consent Informed consent was obtained from all individual participants included in the study.

Conflict of Interest The authors declare that they have no conflict of interest.

Open Access This article is distributed under the terms of the Creative Commons Attribution 4.0 International License (http://creativecommons.org/licenses/by/4.0/), which permits unrestricted use, distribution, and reproduction in any medium, provided you give appropriate credit to the original author(s) and the source, provide a link to the Creative Commons license, and indicate if changes were made.

\section{References}

1. Ellsberg M, Jansen HA, Heise L, Watts CH, Garcia-Moreno C. Intimate partner violence and women's physical and mental health in the WHO multi-country study on women's health and domestic violence: an observational study. Lancet. 2008;371(9619):1165-72.

2. Rees S, Silove D, Chey T, Ivancic L, Steel Z, Creamer M, et al. Lifetime prevalence of gender-based violence in women and the relationship with mental disorders and psychosocial function. JAMA. 2011;306(5):513-21.

3. World Health Organization (WHO). Global and regional estimates of violence against women: prevalence and health effects of intimate partner violence and non-partner sexual violence. Geneva: World Health Organization; 2013.

4. Tsirigotis K, Łuczak J. Emotional intelligence of women who experience domestic violence. Psychiatry Q. 2016;87(1):165-76.

5. Kaufman KG, Jasinski JL. Dynamics and risk factors in partner violence. In: Jasinski JL, Williams LM, editors. Partner Violence. London: Stage Publications; 1998. p. 1-44.

6. Mellibruda J. Wybrane problemy patologii życia rodzinnego [selected problems of pathology in family life]. In: Strelau J, editor. Psychologia [Psychology], vol. III. Gdańsk: GWP; 2007. p. 750-63. in Polish.

7. Martinez-Torteya C, Anne Bogat G, von Eye A, Levendosky AA. Resilience among children exposed to domestic violence: the role of risk and protective factors. Child Dev. 2009;80(2):562-77.

8. Labronici LM. Resilience in women victims of domestic violence: a phenomenological view. Texto contexto-enfer. 2012;21(3):625-32.

9. Council of Europe. Council of Europe Convention on preventing and combating violence against women and domestic violence (Vol. CETS no.210). 2011.

10. United Nations (UN). Declaration on the Elimination of Violence against Women. New York: UN, 1993.

11. Anderson KM, Renner LM, Danis FS. Recovery: resilience and growth in the aftermath of domestic violence. Violence Against Women. 2012;18(11):1279-99.

12. Sasal HD. Niebieskie Karty [Blue Cards]. PARPA: Warszawa; 1998. in Polish

13. Tarzia L, Murray E, Humphreys C, Glass N, Taft A, Valpied J, et al. I-DECIDE: an online intervention drawing on the psychosocial readiness model for women experiencing domestic violence. Womens Health Issues. 2016;26(2):208-16.

14. Sutherland MA, Fantasia HC, Hutchinson MK. Screening for intimate partner and sexual violence in college women: missed opportunities. Womens Health Issues. 2016;26(2):217-24. 
15. Garmezy N. (1973). Competence and adaptation in adult schizophrenic patients and children at risk. In: SR Dean, editors. Schizophrenia: the first ten dean award lectures (s. 163-204). New York: MSS Information Corp.

16. Block JH, Block J. The role of ego-control and ego-resiliency in the organization of behavior. In: Collins WA, editor. The Minnesota symposia on child psychology, vol. 13. Hillsdale: Erlbaum; 1980. p. 39-101.

17. Block JH, Kremen AM. IQ and ego-resiliency: conceptual and empirical connections and separateness. J Pers Soc Psychol. 1996;70:349-61.

18. Bergeman CS, Wallace KA. Resiliency in later life. In: Merluzzi TM, Whitman TL, editors. Life span perspectives on health and illness. Mahwah: Erlbaum; 1999. p. 207-25.

19. Davydov DM, Stewart R, Ritchie K, Chaudieu I. (2010). Resilience and mental health. 30(5):479-495.

20. Charney DS. Psychobiological mechanisms of resilience and vulnerability: implications for successful adaptation to extreme stress. Am J Psychiatry. 2004;161:195-216.

21. Humphreys J. Resilience in sheltered battered women. Issues Ment Health Nurs. 2003;24:137-52.

22. Luthar SS, Cicchetti D, Becker B. The construct of resilience: a critical evaluation and guidelines for future work. Child Dev. 2000;71:543-62.

23. Egeland B, Carlson EA, Sroufe LA. Resilience as process. Dev Psychopathol. 1993;5:517-28.

24. Masten AS. Ordinary magic: resilience processes in development. Am Psychol. 2001;56:227-38.

25. Cicchetti D. Resilience under conditions of extreme stress: a multilevel perspective. World Psychiatry. 2010;9:145-54

26. Wathen CN, MacGregor JC, Hammerton J, Coben JH, Herrman H, Stewart DE, et al. Priorities for research in child maltreatment, intimate partner violence and resilience to violence exposures: results of an international Delphi consensus development process. BMC Public Health. 2012;12:684.

27. Kassis W, Artz S, Scambor C, Scambor E, Moldenhauera S. Finding the way out: a non-dichotomous understanding of violence and depression resilience of adolescents who are exposed to family violence. Child Abuse Negl. 2013;37:181-99.

28. Herreira TT, Labronici LM, Aparecida Barbosa Merighi M, Raimondo ML. The process of resilience in women who are victims of domestic violence: a qualitative approach. Cogitare Enfermagem. 2014;19(3):395-401.

29. Gąsior K, Chodkiewicz J, Cechowski W. Kwestionariusz Oceny Prężności (KOP-26). Konstrukcja i właściwości psychometryczne narzędzia [resilience in adults-characteristics and Measurmentquestionnaire KOP-26]. Pol Forum Psychol. 2016;21(1):76-92. in Polish with Summary in English

30. Werner EE, Smith RS. Vulnerable but invincible: a study of resilient children. New York: McGraw-Hill; 1982.

31. Kaczmarek Ł. Skala Sprężystości Psychicznej-polska adaptacja Ego Resiliency Scale [Psychological Resiliency Scale-Polish Adaptation of Ego Resiliency Scale]. Czas Psychol. 2011;17:263-5. in Polish

32. Polska SS. Statistica PL. StatSoft: Kraków; 2015.

33. Deshpande S. Contemporary India: a sociological view. New Delhi: Penguin Books; 2003.

34. Borooah VK. Caste, inequality, and poverty in India. Rev Dev Econ. 2005;9(3):399-414.

35. Moeller-Saxone K, Davis E, Stewart DE, Diaz-Granados N, Herrman H. Promoting resilience in adults with experience of intimate partner violence or child maltreatment: a narrative synthesis of evidence across settings. J Public Health. 2015;37(1):125-37.

36. Fergusson DM, Horwood LJ, Ridder EM. Partner violence and mental health outcomes in a New Zealand birth cohort. J Marriage Fam. 2005;67:1103-19.

37. Mechanic M, Weaver T, Resick P. Mental health consequences of intimate partner abuse: a multidimensional assessment of four different forms of abuse. Violence Against Women. 2008;14:634-54.

38. Waldrop AE, Resick PA. Coping among adult female victims of domestic violence. J Fam Violence. 2004;19:291-302.

39. Coker AL, Davis KE, Arias I, Desai S, Sanderson M, Brandt HM, et al. Physical and mental health effects of intimate partner violence for men and women. Am J Prev Med. 2002;23:260-8.

40. Straight ES, Harper FWK, Arias I. The impact of partner psychological abuse on health behaviors and health status of college women. J Interpers Violence. 2003;18:1035-54.

41. Saakvitne KW, Tenne H, Affleck G. Exploring thriving in the context of clinical trauma theory: constructivist self-development theory. J Soc Issues. 1998;54:279-99.

42. Freud S. (1916). Leonardo da Vinci: a psychosexual study of an infantile reminiscence; translated by a.A. Brill: Moffat, yard \&co.

43. Seligman M, Walker E, Rosenhan D. Abnormal psychology. 4th ed. New York: W.W. Norton; 2002.

Konstantinos Tsirigotis, Professor, Ph.D. is a clinical psychologist and psychotherapist, Head of Department of Psychology, The Jan Kochanowski University in Kielce, Piotrków Trybunalski Branch, Poland

Joanna Luczak, Ph.D. is a health psychologist and assistant professor, Department of Psychology, The Jan Kochanowski University in Kielce, Piotrków Trybunalski Branch, Poland 